\title{
The Change of Garment Pressure and Body Measurement by Material of Women's Girdle
}

\author{
Jee Hye Park ${ }^{1}$, Jong Suk Chun ${ }^{2}$ \\ ${ }^{1}$ Department of Clothing \& Textile, Yonsei University, Seoul, 120-749, Korea \\ ${ }^{2}$ Professor, Department of Clothing \& Textile, Yonsei University, Seoul, 120-749, Korea
}

\begin{abstract}
Objective: The aim of this study was to investigate the appropriate elasticity of the textile material used for making women's girdle. Background: The elastic textiles have been used for making girdle. The hard type girdle gave high pressure on the body to make slim look. However, excessively high garment pressure caused negative effect to human bodies. This study studied the material giving proper garment pressure in girdle. Method: In this study five experimental girdles were made fabrics with various elasticities. The change of garment pressures and body girths were measured after subjects wearing the experimental girdles. The garment pressure was measured at 10 points. Body girths measured at abdomen, hip, and thigh. Results: The garment pressure of the commercial girdle was high at side of waistband, side femur and back gluteal fold. The experimental girdles made with high elasticity material definitely lowered garment pressure at those points. After wearing experimental girdle their abdomen and hip girths measurements were decreased. But, thigh girth was not reduced. Conclusion: The girdle made with excellent elasticity materials reduced garment pressure significantly and it made body slim as much as the commercial girdle except the thighs. Application: This study provides guideline for the developing girdle that applying optimum range of garment pressure with body slim effect.
\end{abstract}

Keywords: Girdle, Garment pressure, Textile, Elasticity

\section{Introduction}

인체를 일정한 틀에 맞추어 형태를 유지하기 위한 옷의 착용은 르네상스시대 후반부터 서구의 복식 역사를 통해 400년 이상 지속되어 왔다(Steele, 2001). 체형보정 욕구 를 충족시키기 위한 기능성 속옷 착용은 현대에도 이루어 지고 있다. 각종 매체를 통해 판매되고 있는 체형보정기 능을 갖는 속옷들은 파운데이션 (foundation), 콘트롤웨어 (controlwear), 쉐입웨어(shapewear) 등으로 분류되고 있 다. 이중 거들은 하반신 체형을 날씬하게 보이도록 해주기 위해 착용되는 옷이다(Apsan, R., 2006).
우리나라 20대 여성들이 선호하는 체형은 키가 크고 마른 체형이며 허리가 가늘고 엉덩이가 크지 않으며, 허벅지가 날씬한 체형이다(Jung and Lee, 1993; Lee et al., 1997). 이와 같이 우리나라 20대 여성들은 하반신이 마른 체형을 선호하기 때문에 이상적인 체형을 표현하기 위해 거들을 착 용한다(Son, 1992). 거들은 탄성이 강한 소재를 사용하여 신체보다 작은 치수로 제작한 속옷이다. 거들은 착용자의 신 체를 강하게 압박하여 날씬한 하체 실루엣을 나타내기 때문 에 지나치게 높은 의복압으로 인해 건강에 해롭다고 주장되 기도 한다. 의복압이 지나치게 높은 옷을 착용한 경우 골격, 내장 등의 물리적 변형뿐 아니라 혈액순환 - 소화기능을 해 칠 수 있으며(Park and Kim, 1990) 심리적 장애도 발생시

Corresponding Author: Jong Suk Chun. Department of Clothing \& Textile, Yonsei University, Seoul, 120-749, Korea.

Mobile: +82-10-2123-3107, E-mail: jschun@yonsei.ac.kr

Copyright@2012 by Ergonomics Society of Korea(pISSN:1229-1684 eISSN:2093-8462 http://www.esk.or.kr). All right reserved.

(c) This is an open-access article distributed under the terms of the Creative Commons Attribution Non-Commercial License(http://creativecommons.org/licenses/by-nc/3.0/), which permits unrestricted non-commercial use, distribution, and reproduction in any medium, provided the original work is properly cited. 
킬 수 있다(Jeong and Kim, 2006). 그러나 생리적 장애와 심리적 불쾌감을 유발하지 않고, 인체의 실루엣을 아름답게 표현할 수 있는 적정 의복압의 범위를 과학적으로 규명한 연 구나 인체부위 별로 적정한 의복압을 제안한 연구는 활발하 게 보고되고 있지 않다.

따라서 본 연구는 거들 소재의 신장률을 부위별로 변화시 켰을 경우 나타나는 의복압 변화를 고찰하여 특정 부위의 의복압이 지나치게 높지 않은 거들의 개발 가능성을 연구하 였다.

\subsection{Function of girdle}

거들은 하반신(lower torso \& leg)의 형태를 정형하기 위 해 여성들이 착용하는 속옷으로, 신축성이 다양한 소재로 제 작된다. 거들은 주로 배와 엉덩이의 실루엣이 매끈하게 보 이도록 하기 위해 착용하며, 초기 형태는 허리, 배, 둔부와 허벅지 상단까지를 매끄럽게 성형시키는 통 형태의 거들 (Criss-Cross Girdle)이 주를 이루었으나 여성들의 바지 착용이 증가함에 따라 양쪽 다리를 각각 감싸는 바지 형태 거들(Panty-Girdle)의 착용이 일반화되었다. 이외에도 허 리 실루엣이 매끈하게 보이도록 하기 위해 허리단의 위치가 늑골 하단까지 올라가도록 디자인되기도 한다(Calasibetta, 1986).

거들은 탄성이 강한 소재를 사용하여 신체치수보다 작게 제작하므로 착용 후 신체에 가해지는 의복압이 큰 속옷이다. 이러한 문제점이 상존하는 의류임에도 불구하고, 여성들은 하반신의 체형을 매끈하고 날씬하게 보이도록 하여 정신적 인 만족감을 갖기 위해 거들을 착용한다(Lee, 2003). 최근 에는 체형보정기능 속옷 시장이 활성화됨에 따라 소비자가 자신이 원하는 보정효과에 따라 적합한 스타일을 선택하도 록 하고 있다(www.macys.com). 이와 같이 체형보정 기능 성 속옷에 대한 수요가 증가함에 따라 체형보정기능을 반영 하는 부위를 세분화하여 제품개발이 이루어지고 있으며, 의 류의 명칭도 착용 목적을 더 직접적으로 표현하는 용어가 사용되는 경향도 보인다. 예를 들어 엉덩이 실루엣을 돋보이 게 하는 허벅지길이의 거들은 'Mid Thigh Body Shaper with Buttock Enhancer'라고 명칭하기도 한다.

거들을 제작하는데 사용되는 소재는 대부분 강한 탄성과 신장률을 가지고 있으며 일반적으로 아랫배의 돌출을 억제 하기 위해 복부를 커버하는 부위는 비탄성 소재를 사용하여 제작한다(Ewing, E., 2010).

거들 착용 후 나타나는 신체치수변화를 연구한 선행연구 들은 거들 착용 후 엉덩이 돌출점을 포함하여 전체적으로 높이가 상승하며 허리둘레, 복부둘레, 엉덩이둘레치수는 작 아진다고 하였다(Park and Kim, 2007). 또한 둔부를 가운
데로 모아주고 위로 올려주는 효과와 허리를 가늘게 보이게 해주고 처진 배를 올려주는 입체적 체형보정의 효과가 있다 고 하였다(Park, 2001; Choi and Kim, 1993; Park and Kim, 1990). 그러나 이러한 체형보정효과를 가지게 되는 것에 대 한 대가로 거들 착용자는 강한 의복압을 감수해야 하는 것으 로 인식되어 왔다.

\subsection{Garment pressure and subjective sensation}

의복압은 의복이 인체를 조이는 정도로 의복 중량이나 의 복 형태에 따라서 달라진다(Kang, 1999). 의복압은 객관적 으로 측정이 가능하나 동일한 의복압에 대해서 착용자가 느 끼는 주관적인 구속감은 개인의 체지방과 근육조성에 따라 다르다(Park and Choi, 2007). 또한 개인적인 경험이나 생 리적 민감도에 따라서도 동일한 의복압에 대한 착용자의 쾌 적함의 정도는 차이를 나타낼 수 있다(Na and Lee, 2010). 이와 같이 의복압에 대한 주관적 감각은 개인의 자라온 환 경이나 여러 가지 사회적 배경 및 생체 신경계의 상호 작용 에 의해 영향을 받는다(Torgén and Swerup, 2002). 그러 나 일반적으로 거들은 의복압이 높은 대표적 의류로 인식되 고 있으며, 선행연구는 여성들이 거들을 착용하지 않는 이 유를 압박감이 지나치게 커서 답답하고 착 탈의가 어렵기 때문이라고 하였다(Kim, 1991).

선행연구는 지나치게 강한 의복압은 인체 건강을 해치나 적절한 의복압은 신체 활동을 용이하게 하며, 작업 능률을 향상시킬 뿐 아니라 건강의 유지 및 증진에도 도움이 된다고 하였다. 예를 들어 화상 환자들이나 외상 수술 환자들은 수 술 후 압박의류를 착용함으로써 피부조직 회복과 수술로부 터의 빠른 회복을 돕는다(Shelton et al., 1998; Tazelaar et al., 1999; Dirik et al., 2001; Engrav et al., 2010). 의료 용 압박 스타킹은 수술 후 부종을 방지하기 위해 착용하며 (Hafner, 2000) 오랫동안 서 있는 직업의 여성들도 부종을 방지하고 하체 혈액순환을 원활하게 하기 위하여 압박기능 스타킹을 착용한다(Ng and Hui, 1999). 그러나 의복압이 지 나치게 크면 혈류량을 감소시켜 근육피로와 혈류순환 장해 를 일으키며 소화기능을 저하시키고 피로를 증가시킬 수 있 다. 지나치게 의복압이 큰 옷을 장기간 착용하였을 경우 신 체 내 장기의 위치와 형태가 변형되어 소화불량이나 십이지 장염 등이 발생할 가능성이 있다(Park and Kim, 1990).

이와 같이 과도한 의복압은 인체에 부정적인 영향을 미 치나 적정 범위의 의복압은 생체기능을 향상시킬 수도 있 으므로 선행연구들은 적절한 범위의 의복압을 파악하기 위 해 의복압과 주관적 감각 평가의 관계를 분석하거나(Shim and Choi, 1993; Kim and Hahm, 1994; Jeong and Kim, 2006; Na and Lee, 2010) 의복압과 인체생리반응의 관계 
를 조사하였으며, 생리적으로 장해가 없는 의복압의 범위를 연구하여 허용한계 의복압은 $40 \mathrm{~g} / \mathrm{cm}^{2}$ 라고 하였다(Jeong, 2005).

\section{Method}

\subsection{Sample girdle construction}

본 연구의 실험용 거들은 시판되고 있는 대표적인 국내브 랜드의 스타일(GR2581)이었다. 이 거들은 허리높이가 낮고 허벅지길이의 바지 형 기본스타일이다. 이 거들은 복부(@), 골반과 허벅지 뒤쪽((b)), 허벅지 앞쪽(c), 허벅지 안쪽(d), 둔부(@), 둔부 하단(f) 부위를 감싸는 6 개 패턴으로 구성 되었다(Figure 1).

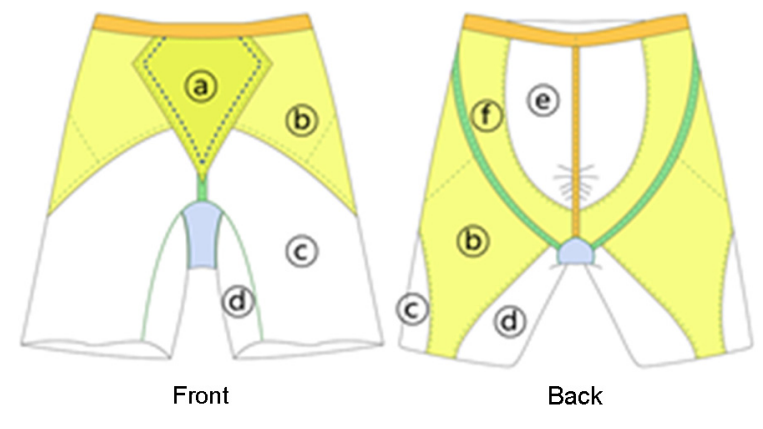

\begin{tabular}{|c|c|c|c|c|c|c|}
\hline \multirow[b]{2}{*}{ Parts } & \multicolumn{5}{|c|}{ Experimental girdle } & \multirow{2}{*}{$\begin{array}{c}\begin{array}{c}\text { Commercial } \\
\text { girdle }\end{array} \\
\mathrm{F}\end{array}$} \\
\hline & A & B & $\mathrm{C}$ & D & $\mathrm{E}$ & \\
\hline (a) & M1 & M2 & M3 & M3 & M4 & M7+M6 \\
\hline (b) & M1 & M2 & M2 & M3 & M3 & M5+M6 \\
\hline (c) & M1 & M1 & M1 & M1 & M1 & M5 \\
\hline (d) & M1 & M1 & M1 & M1 & M1 & M5 \\
\hline (e) & M1 & M1 & M1 & M1 & M1 & M5 \\
\hline (f) & M1 & M3 & M3 & M3 & M3 & M5+M6 \\
\hline
\end{tabular}

Figure 1. Materials of sample garments

본 연구에서는 거들에 사용되는 직물의 신장률을 부위별 로 달리하였을 때 나타나는 신체부위별 의복압 변화를 파악 하기 위해서 부위별로 신장률이 다른 소재를 사용하여 실험 용 거들을 제작하였다. $\mathrm{M} 1$ 은 신장률이 가장 높은 소재였고 (Warp 29\%, Weft 47\%) M2는 경사방향의 신장률보다 위 사방향의 신장률이 높은 소재였다(Warp 14\%, Weft 40\%). $\mathrm{M} 3$ 은 경사와 위사방향 신장률이 낮은 소재였다(Warp $4 \%$,
Weft $8 \%$ ). M4는 경사와 위사방향 신장률이 $0 \%$ 인 면 소재 였다(Table 1). 소재의 신장률은 KS K 0352에 따라 측정 하였고 $1 \mathrm{~kg}$ 의 하중에서 3 분 후 늘어난 시험편의 길이 변화 를 측정하여 신장률을 산출하였다(Figure 2).

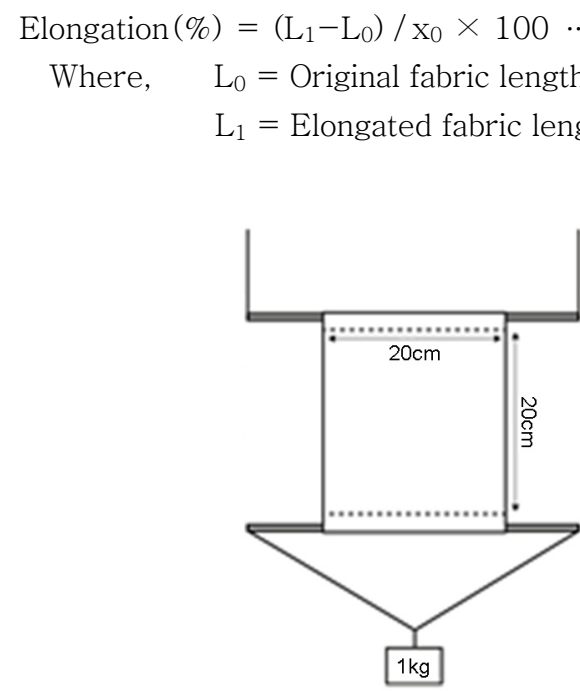

Figure 2. Elongation test

실험복은 복부부위 패턴(a) 과 골반과 허벅지 뒤쪽을 감 싸는 패턴(b) 의 소재 신장률을 달리하였을 경우 나타나는 의복압과 신체치수의 변화를 파악하기 위하여 (a)과 (b)부위 의 소재 사용을 달리하여 제작하였다. 실험복 $\mathrm{A}$ 는 의복압이 가장 적은 거들 착용 시 의복압을 파악하기 위해 모든 부위 를 가장 신축성이 좋은 소재(M1)로 제작하였다. 실험복 B 는 복부(@) 와 골반과 허벅지 뒤쪽(b)을 가로방향으로 신 축성이 좋은 소재(M2)로 제작하였다. 실험복 $\mathrm{C}$ 는 복부(a) 는 신축성이 적은 소재(M3)를 사용하고 골반과 허벅지 뒤 쪽 패턴(b) 는 가로방향으로 신축성이 좋은 소재(M2)를 사 용하였다. 실험복 $\mathrm{D}$ 는 복부(a)와 골반 및 허벅지 뒤쪽(b) 에 신축성이 적은 소재(M3)를 사용했다. 실험복 $\mathrm{E}$ 는 복부 패턴(@)은 신축성이 없는 소재(M4)를 사용하고 패턴(b) 는 신축성이 적은 소재 $(\mathrm{M} 3)$ 를 사용하였다. 실험복 $\mathrm{B} \sim \mathrm{E}$ 는 둔부 하단을 감싸는 패턴(f)을 신축성이 적은 $\mathrm{M} 3$ 로 제작 하였다 비교용 샘플로 사용한 시판 거들은 경사나 위사방 향의 신장률이 $11 \%$ 로 동일한 직물(M5)을 복부(@)를 제외 한 모든 부위에 사용하였고 골반과 허벅지 뒤쪽(b) 과 둔부 하단에는 경사방향 신장률이 $(21 \%)$ 위사방향 신장률 $(10 \%)$ 보다 높은 직물을 추가로 사용하였다(Table 1). 
Table 1. Characteristic of materials

\begin{tabular}{c|c|c|c}
\hline \multirow{2}{*}{ Material } & \multirow{2}{*}{ Fiber contents(\%) } & \multicolumn{2}{|c}{ Elongation rate } \\
\cline { 3 - 4 } & & Warf & Weft \\
\hline M1 & Nylon/Spandex(80/20) & $29 \%$ & $47 \%$ \\
\hline M2 & Nylon/Spandex(80/20) & $14 \%$ & $40 \%$ \\
\hline M3 & Nylon/Spandex(84/16) & $4 \%$ & $8 \%$ \\
\hline M4 & Cotton(100) & $0 \%$ & $0 \%$ \\
\hline M5 & Nylon/Spandex & $11 \%$ & $11 \%$ \\
\hline M6 & Nylon/Spandex & $21 \%$ & $10 \%$ \\
\hline M7 & Nylon/Spandex & $4 \%$ & $31 \%$ \\
\hline
\end{tabular}

\subsection{Subjects}

실험은 국내 여성(15 70세)의 허리둘레와 엉덩이둘레의 이원분포표(KS K 9404)에서 높은 분포를 보이는 70 94 치수(허리둘레 $67 \sim 73 \mathrm{~cm}$ 엉덩이둘레 89 95cm)에 해당하 는 3 명의 피험자들을 대상으로 이루어졌다. 피험자들의 신체 치수는 허리둘레가 $66.0 \sim 72.5 \mathrm{~cm}$, 배둘레가 $83.5 \sim 87.0 \mathrm{~cm}$, 엉덩이둘레가 91.0 97.0cm, 허벅지둘레가 $52.0 \sim 55.5 \mathrm{~cm}$ 였다(Table 2). 피험자 1은 70-94 사이즈 중 작은 체형에 속하며, 피험자 3 은 큰 체격에 속했다. 피험자 2 는 중간 정 도의 체격이었다.

Table 2. Body measurements of subjects

\begin{tabular}{c|c|c|c|c}
\hline Simension & 1 & 2 & 3 & Average \\
\hline Waist girth $(\mathrm{cm})$ & 66.0 & 69.0 & 72.5 & 69.2 \\
\hline Abdomen $(\mathrm{cm})$ & 84.0 & 83.5 & 87.0 & 84.8 \\
\hline Hip girth $(\mathrm{cm})$ & 91.0 & 94.5 & 97.0 & 94.2 \\
\hline Thigh girth $(\mathrm{cm})$ & 52.0 & 52.5 & 55.5 & 53.3 \\
\hline
\end{tabular}

\subsection{Measuring garment pressure and body girth}

5 종의 실험복과 시판 거들을 착용하였을 때 피험자들의 의복압을 10 개 부위에서 5 회 반복 측정하였다(Table 3 ). 측정부위는 선행연구(Nam and Lee, 2002)를 참고하여 전 면 4부위(1) (4)), 측면 3부위((5) (7)), 후면 3부위(8) (10) 를 설정하였다. 의복압 측정기기는 AMI 3037 (SANKO TSUSHO CO.LTD.JAPAN)이었다.

실험용 거들 착용 후 나타나는 신체치수변화는 ISO 8559 에 따라 배둘레, 엉덩이둘레, 허벅지둘레에서 측정하였다. 실 험복 착용 후 신체치수의 변화율 $(\%)$ 은 수식 (2)로 측정하 였다.

Dimensional Change rate $(\%)=\left(\mathrm{y}_{1}-\mathrm{y}_{0}\right) / \mathrm{y}_{0} \times 100$

Where, $\quad \mathrm{y}_{0}=$ Body measurement before wearing girdle

$\mathrm{y}_{1}=$ Body measurement after wearing girdle

\section{Results}

\subsection{Garment pressure}

시판 거들인 실험복 $\mathrm{F}$ 를 착용하였을 때 의복압을 측정 한 결과 허리옆점 $(\mathrm{SW})$, 대퇴골점 $(\mathrm{SF})$ 과 둔부고랑점(BGT) 에서 $2.0 \mathrm{Kpa}$ 이상의 높은 의복압을 나타냈으며 배돌출점 $(\mathrm{FA})$, 둔부돌출점 $(\mathrm{BBP})$, 허벅지점들 $(\mathrm{FI}, \mathrm{ST}, \mathrm{FT})$ 에서도 $1.5 \mathrm{Kpa}$ 이상의 비교적 높은 의복압을 나타냈다(Table 4). 모든 패턴조각을 신장률이 우수한 소재(M1)으로 제작한 실 험복 $\mathrm{A}$ 는 모든 측정점에서 $1 \mathrm{Kpa}$ 미만의 낮은 의복압을 나 타내었고 골반과 허벅지 뒤쪽 패턴(b) 을 위사방향의 신장

Table 3. Measuring points of garment pressure

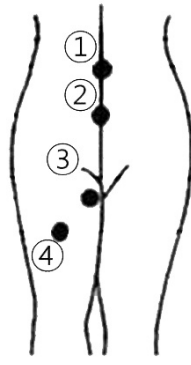

Front

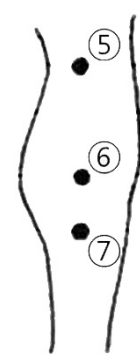

Side

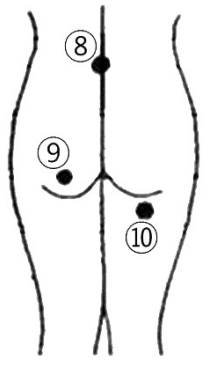

Back

\begin{tabular}{|c|c}
\hline 1 & Front Waist Band(FW) \\
\hline 2 & Front Abdomen(FA) \\
\hline 3 & Front Inseam(FI) \\
\hline (4) & Front Thigh(FT) \\
\hline (5) & Side Waist Band(SW) \\
\hline (6) & Side Femur(SF) \\
\hline$(7)$ & Side Thigh(ST) \\
\hline 8 & Back Waist Band(BW) \\
\hline (9) & Back Buttock Protrusion(BBP) \\
\hline (1) & Back Gluteal Fold(BGF) \\
\hline
\end{tabular}


률이 경사방향의 신장률보다 3 배 정도 높은 소재(M2)로 제 작한 실험복 $\mathrm{B}$ 와 $\mathrm{C}$ 는 허리옆점 $(\mathrm{SW})$ 과 대퇴골점 $(\mathrm{SF})$ 를 제 외한 모든 점에서 $1 \mathrm{Kpa}$ 미만의 낮은 의복압을 나타내었다. 골반과 허벅지 뒤쪽 패턴(b) 을 위사와 경사방향의 신장률이 낮은 소재 $(\mathrm{M} 3)$ 로 제작한 실험복 $\mathrm{D}$ 와 $\mathrm{E}$ 는 허리앞점 $(\mathrm{FW})$, 허리옆점 $(\mathrm{SW})$, 배돌출점 $(\mathrm{FA})$, 대퇴골점 $(\mathrm{SF})$, 엉덩이돌출점 $(\mathrm{BBP})$, 둔부고랑점 $(\mathrm{BGF})$ 에서 $1 \mathrm{Kpa}$ 이상의 의복압을 나타

Table 4. Garment pressure of experimental garments

\begin{tabular}{c|c|c|c|c|c|c|c}
\hline \multicolumn{2}{c|}{ Body parts } & A & B & C & D & E & F \\
\hline \multirow{4}{*}{$\begin{array}{c}\text { Waist } \\
\text { band line }\end{array}$} & FW & 0.52 & 0.60 & 0.95 & 1.13 & 1.23 & 1.23 \\
\cline { 2 - 8 } & SW & 1.02 & 1.11 & 1.34 & 1.29 & 1.60 & 2.76 \\
\cline { 2 - 8 } & BW & 0.60 & 0.80 & 0.58 & 0.73 & 1.05 & 0.80 \\
\hline Abdomen & FA & 0.61 & 0.66 & 0.99 & 1.17 & 1.25 & 1.50 \\
\hline \multirow{2}{*}{$\begin{array}{c}\text { Hip } \\
\text { line }\end{array}$} & SF & 0.87 & 1.13 & 1.06 & 2.09 & 2.15 & 2.52 \\
\cline { 2 - 8 } & BBP & 0.87 & 0.65 & 0.87 & 1.19 & 1.24 & 1.92 \\
\hline \multirow{4}{*}{$\begin{array}{c}\text { Thigh } \\
\text { line }\end{array}$} & FI & 0.72 & 0.61 & 0.81 & 0.74 & 0.72 & 1.71 \\
\cline { 2 - 8 } & FT & 1.02 & 0.81 & 0.91 & 0.96 & 0.96 & 1.68 \\
\cline { 2 - 8 } & ST & 0.79 & 0.80 & 0.72 & 0.80 & 0.85 & 1.73 \\
\cline { 2 - 8 } & BGT & 0.96 & 0.84 & 0.58 & 1.42 & 1.23 & 2.21 \\
\hline
\end{tabular}

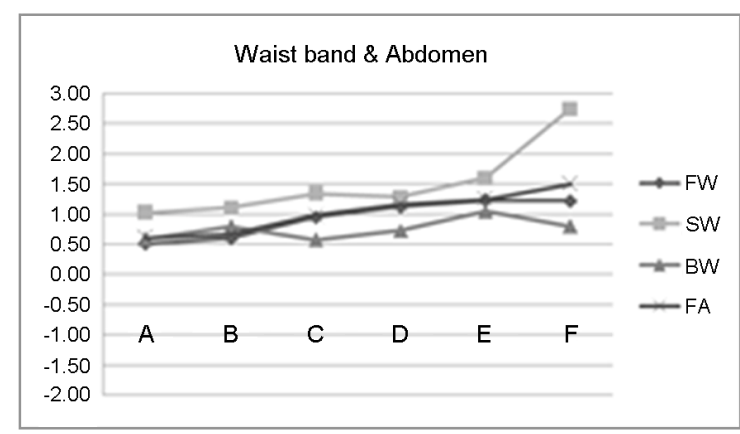

Figure 3. Garment pressure at waist band and abdomen area

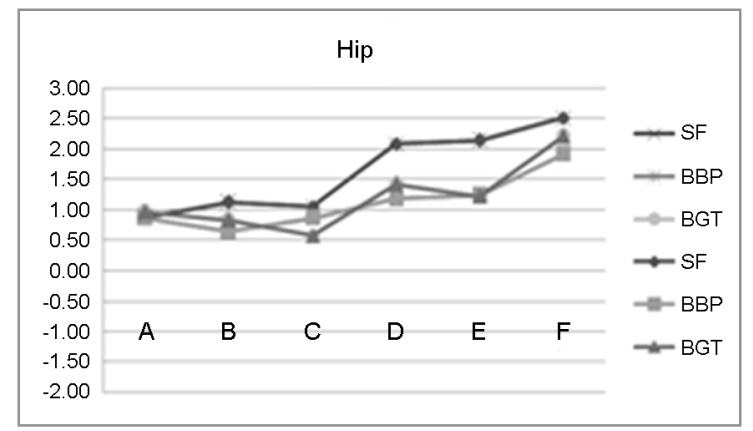

Figure 4. Garment pressure at hip area
냈으며 특히 대퇴골점의 의복압은 $2 \mathrm{KPa}$ 이상이었다. 허리 단 부위의 의복압은 모든 실험복에서 측면이 전면이나 후면 보다 높으며, 배부위의 의복압보다도 높았다(Figure 3). 엉 덩이부위는 대퇴골점의 의복압이 둔부고랑점이나 엉덩이돌 출점보다 높은 편이었다(Figure 4).

\subsection{Change of body measurements}

시판 거들인 실험복 $\mathrm{F}$ 를 착용하였을 때 하반신의 둘레치 수를 측정한 결과 엉덩이둘레는 $1.13 \%$ 감소하였고 허벅지 둘레는 $3.11 \%$ 로 크게 감소하였다. 그러나 배둘레는 $0.68 \%$ 증가하였다. 실험복 $\mathrm{A}$ 는 배둘레 $(-0.41 \%)$ 와 엉덩이둘레 $(-0.35 \%)$ 가 미세하게 감소하였으나 거의 변화가 없었다. 실험복 $\mathrm{B}, \mathrm{D}, \mathrm{E}$ 는 배둘레에서 $-0.81 \sim 0.99 \%$ 의 치수감소효 과가 나타났고 엉덩이둘레에서는 거의 변화가 없었다. 실험 복 $\mathrm{C}$ 는 신체치수감소효과가 없었다, 실험복 $\mathrm{C}$ 는 복부부위 (a) 에 신장률이 낮은 소재를 사용하였음에도 불구하고 해 당부위에 신장률이 높은 소재를 사용한 실험복 B보다도 배 부위의 신체치수감소효과가 나타나지 않았다. 모든 실험용 제작 거들 $(\mathrm{A} \sim \mathrm{E})$ 은 허벅지둘레치수를 감소시키지 못하였다 (Table 5). 실험복 A E는 허벅지둘레는 감소시키지 못하였 고 엉덩이둘레는 0.35 0.42\% 감소시키거나(A, D) $0.36 \%$ 증가시키는 경향이 나타나기도 하였다 $(\mathrm{B}, \mathrm{D})$. 그러나 시판 거들인 $\mathrm{F}$ 는 허벅지둘레와 엉덩이둘레를 가장 크게 감소시켰 다. 따라서 배와 허리둘레의 증가는 이와 관련이 있을 수 있 다고 생각된다.

Table 5. Change of body measurement

\begin{tabular}{c|c|c|c|c|c|c}
\hline Sample & A & B & C & D & E & F \\
\hline Body parts & & & & & & \\
\hline Waist girth & 1.70 & 1.98 & 2.44 & 1.94 & 2.42 & 2.19 \\
\hline Abdomen girth & -0.41 & -0.97 & 0.79 & -0.81 & -0.99 & 0.68 \\
\hline Hip girth & -0.35 & 0.36 & 0.36 & -0.42 & 0.00 & -1.13 \\
\hline Thigh girth & 1.25 & 0.65 & 1.57 & 1.25 & 0.65 & -3.11 \\
\hline
\end{tabular}

\subsection{Comparison of body measurements and garment pressure}

의복압 대비 치수감소효과가 효율적인 거들을 선별하기 위하여 신체부위별로 실험용 거들 착용 후 신체치수의 변화 와 의복압을 상호 비교 분석한 결과 시판 거들 $(\mathrm{F})$ 은 치수감 소효과가 크나 허벅지둘레의 의복압이 1.68 2.21Kpa로 비 교적 높은 것으로 나타났다. 엉덩이부위는 허벅지부위보다는 
치수감소효과는 작으나 의복압은 더 높은 것으로 나타났다. 실험복 $\mathrm{D}$ 와 $\mathrm{E}$ 는 대퇴골점 $(\mathrm{SF})$ 의 의복압이 높음에도 불구하 고 엉덩이부위의 치수감소효과는 거의 없는 것으로 나타났 다. 반면 실험복 $\mathrm{A}$ 는 전반적으로 의복압이 가장 낮았으며 미약하게 배와 엉덩이 치수를 감소시켰다. 실험복 $\mathrm{B}$ 는 실험 복 $\mathrm{A}$ 와 유사한 정도의 낮은 의복압을 나타냈으나 배둘레치 수 감소효과가 뚜렷하였다.

허리부위와 배부위를 살펴보면, 허리앞점 $(\mathrm{FW})$ 과 배돌출 점(FA), 허리옆점 $(\mathrm{SW})$ 의 의복압은 실험복 $\mathrm{A}$ 와 $\mathrm{B}$ 가 타 실 험복에 비해 낮게 나타났으며, 특히 실험복 $\mathrm{B}$ 는 의복압이 낮 음에도 불구하고 배부위의 신체둘레치수가 감소하였다. 실험 복 $\mathrm{C}$ 는 의복압은 허리앞점, 배돌출점, 허리옆점의 의복압이 실험복 $\mathrm{A}, \mathrm{B}$ 보다 컸지만 배부위의 둘레치수는 감소하지 않 았다. 실험복 $\mathrm{D}, \mathrm{E}$ 는 배둘레 신체변화율이 실험복 $\mathrm{B}$ 와 거의 비슷하였고 의복압은 실험복 B보다 높았다. 이러한 결과를 종합하여 평가하면 실험복 $\mathrm{B}$ 가 낮은 의복압으로 허리부위와 배부위의 체형을 보정할 수 있는 실험복으로 판단되었다.

엉덩이부위를 살펴보면, 대퇴골( $\mathrm{SF})$, 둔부돌출점 (BBP), 둔부고랑점 $(\mathrm{BGF})$ 의 의복압은 모두 실험복 $\mathrm{A}, \mathrm{B}, \mathrm{C}$ 에서 낮 게 나타났으며 실험복 $\mathrm{D}, \mathrm{E}$ 착용시에는 대퇴골의 의복압이 급격하게 높아지는 것을 알 수 있었다. 다른 부위의 의복압 또한 실험복 $\mathrm{D}, \mathrm{E}$ 에서 높게 나타났다. 엉덩이둘레의 치수 변 화율은 실험복 $\mathrm{A}$ 와 실험복 $\mathrm{D}$ 가 약간 감소하였다. 이러한 결 과를 종합하여 평가하면 실험복 $\mathrm{A}$ 가 낮은 의복압으로 엉덩 이부위를 매끈하게 표현해주는 거들이라고 판단되었다.

이와 같은 결과는 위사방향 신장률이 높은 소재를 복부부 위(a) 와 골반과 허벅지 뒤쪽을 감싸는 부위(b)에 동일하 게 사용하는 방식이 복부부위를 주변보다 신장률이 더 작은 소재를 사용하는 방법보다 더 적은 의복압으로 우수한 보정 효과를 나타낼 수 있음을 보여준다.

\section{Conclusion}

본 연구는 거들의 의복압을 낮추면서 신체치수를 감소시 킬 수 있는 방안을 모색하기 위해 거들 제작에 사용되는 소 재의 신장률을 부위에 따라 변화시켜 의복압과 인체치수변 화를 파악하는 실험을 실시하였다. 본 연구의 주요 분석대상 부위는 배와 엉덩이부위였다. 실험 결과 비교샘플로 사용한 시판용 거들은 엉덩이둘레와 허벅지둘레치수를 감소시켜주 는 효과가 뚜렷하였으나 대퇴부위와 둔부고랑점의 의복압이 높아 의복압을 낮출 수 있는 방안이 필요한 것으로 파악되었 다. 이러한 강한 의복압은 예민한 착용자의 경우에 불쾌한 착용감을 줄 수 있으므로, 의복압을 낮추면서도 복부와 엉덩
이부위의 치수감소효과를 보일 수 있는 거들 제작을 위해 신 축성이 다른 소재를 복부와 골반 및 허벅지 뒤쪽에 배치하여 제작한 5 벌의 실험복의 의복압과 신체치수변화를 비교 분석 한 결과 위사방향의 신장률이 우수한 소재를 복부와 골반 및 허벅지 뒤쪽을 감싸는 부위에 사용함으로써 적은 의복압 으로도 신체치수보정효과를 거둘 수 있음을 파악하였다.

거들 전체를 신장률이 높은 소재로 제작한 실험복 $(\mathrm{A})$ 는 낮은 의복압으로 미세한 신체치수감소효과를 나타내어 신체 치수를 감소시키는 목적보다는 하반신의 실루엣을 매끄럽게 표현하는 목적으로 착용할 제품에 적합한 것이라고 생각된 다. 즉, 경사와 위사방향으로 높은 신장률을 가진 소재로 제 작한 거들은 의복압의 부담이 없이 매끄러운 신체 실루엣을 효과적으로 표현할 수 있음을 보여준다.

본 실험은 3 명의 비교적 적은 숫자의 피험자들을 대상으 로 이루어져 결과를 일반화시키기에는 다소 부족하지만, 부 위별로 신장률이 다른 소재를 사용함으로써 시판 거들보다 편안하면서도 효율적으로 신체를 조형시켜주는 거들의 개발 가능성을 확인하였다. 즉, 강한 의복압이 체형보정효과를 높 여주는 것은 아니며 착용자들이 보정을 필요로 하는 부위에 따라 신장률이 다른 소재를 사용함으로써 소비자의 수요에 맞춘 거들 개발의 가능성을 파악할 수 있었다.

\section{Acknowledgements}

This study was supported by Yonsei University Research Fund of 2011.

\section{References}

Apsan, R., The Lingerie hand book, Workman Publishing, 2006.

Baek, Y. J. and Choi, J. W., Selection of the Measurement Points for Garment Pressure of the Girdle and the All-in-one, The Korean Journal of Community Living Science, 18(4), 609-616, 2007.

Calasibetta, C. M., Essential Terms of Fashion, New York: Fairchild Publications, 1986.

Choi, M. S. and Kim, O. J., A study of the foundation garment manufacturing for the well-balanced somatotype - With middle-age womenhood, Journal of the Korean Society of Clothing and Textiles, 17(2), 247-264, 1993.

Dirik, E., Aydin, A., Kuruk, S and Sahin, B., Limb girdle muscular dystrophy type 2A presenting with cardiac arrest, Pediatric Neurology, 24(3), 235-237, 2001.

Engrav, L. H., Heimbach, D. M., Rivara, F. P., Moore, M. L., Wang, J., 
Carrougfer, G. J., Costa, B., Numhom, S., Calderon, J. and Gibran, N. S., "12-year within-wound study of the effectiveness of custom pressure garment theraphy," BURNS, 36, 975-983, 2010.

Ewing, E., Fashion in underwear. New York: Dover publications, INC. Mineola, 2010.

Hafner, J., Lüthi, W., Hänssle, H., Kammerlander, G. and Bueg, G., Instruction of compression theraphy by means of interface pressure measurement, Dematilogy Surgery, 26, 481-487, 2000.

ISO 8559, Garment construction and anthropometic surveys - Body dimensions, 2010

Jeong, J. R., Effect of skin pressure exerted by foundation on physiological responses and subjective Sensory evaluation, Kyungpook University, 2005.

Jeong, J. R. and Kim, H. E., Comparative evaluation of clothing pressure and subjective sensation exerted by foundation, Journal of the Korean Society of Clothing and Textiles, 30(11), 1531-1537, 2006.

Jung, J. E. and Lee, S. W., A study on real body size and ideal body shape of 18 to 26 year-old women, Journal of the Korean Society of Clothing and Textiles, 17(3), 448-458, 1993.

KS K 9404, Sizing systems for foundation garments.

Kang, M. K., A study on the clothing pressure from wearing of girdle, Wonkwang University, 2000.

Kim, H. E. and Hahm O. S., The clothing pressure of the bodysuits on various sizes and movement, Journal of the Korean society of living environmental system, 1(2), 129-138, 1994

Lee, Y. J., The recognition and the somatotype analysis of the women's lower park of the body for slacks pattern, Journal of the Korean Society of Clothing and Textiles, 22(1), 1998.

Lee, Y. S. and Kim, S. H., A study on a female's contemporary underwear, The Korean journal of community living science, 14(3), 47-57, 2003.

Macy's Official Site, http://www.macys.com/

Na, Y. J. and Lee, D. W., Clothing Pressure Sensation and Discomfort Experience of Skinny Jean, Korean Living Science Association, 19(4), 655-665, 2010

Nam, Y. J. and Lee, J. O., A Study on Feeling of Wearing and Clothing Pressure of Custom-Made Girdles, The Korean Fiber Society, 39(4), 503-513, 2002.

Ng, S. F. F. and Hui, C. L. P., Effect of hem edges on the interface pressure of pressure garmants, Intenational Journal of Clothing Science and Technoligy, 11(5), 251-261, 1999.

Park, E. J., Effect of body shaping by wearing girdle, Journal of the Korean Society of Clothing Industry, 3(3), 235-240, 2001.

Park, J. E. and Kim, H. E., Body shape variations measurements with 3D scanner for wearing foundation, Journal of the Korean Society of Clothing Industry, 9(6), 651-657, 2007.

Park, Y. D. and Kim, H. E., Research: A study on the influence of wearing
- girdle on the various physiological function, Journal of the Korean Home Economics Association, 28(1), 1-7, 1990.

Shelton, F., Barnett, R. and Meyer, E., Full-body interface pressure testing as a method for performance evaluation of clinical support surfaces, Applied Ergonomics, 29(6), 491-497, 1998.

Shim, B. J. and Choi, S. H., Studied on Garment Restraint (III), Journal of the Korean Society of Clothing and Textiles, 17(2), 197-206, 1993.

Shapewear and more, http://www.Shapewearandmore.com/

Steele, V., The corset; A cultural history, 2nd printing, New Haven: Yale University Press, 2001.

Son, H. S., A study on the actual condition of brassiere and girdle for middle and high school girls, 論文集, 32, 45-98, 1992.

Tazelaar, D. J., Neumann, H. A. M. and Roos, K. P., Long cotton wool rolls as compression enhancers in macrosclerotheraphy for varicose vein, Dematology Surgery, 25, 38-40, 1999.

Torgén, M. and Swerup, C. "Individual factors and physical work load in relation to sensory thresholds in a middle-ages reneral population sample." Eur J Appl Physiol Vol.86 (2002), pp.418-427.

\section{Author listings}

Jee Hye Park: rathesia@naver.com

Highest degree: Master's Degree, Department of Clothing \& Textile, Yonsei University

Position title: Master's Degree, Department of Clothing \& Textile, Yonsei University

Areas of interest: Ergonomics

Jong Suk Chun: jschun@yonsei.ac.kr

Highest degree: $\mathrm{PhD}$, Department of Clothing \& Textile, Yonsei University

Position title: Professor, Department of Clothing \& Textile, Yonsei University

Areas of interest: Ergonomics

Date Received : 2012-02-17

Date Revised :2012-04-20

Date Accepted : 2012-04-24 